Resenha de Livro:

\title{
CIRCUITOS DE CORRENTE ALTERNADA: FUNDAMENTOS E PRÁTICA
}

AUTORES: GILMAR BARRETO, CARLOS ALBERTO DE CASTRO JUNIOR, CARLOS ALBERTO FAVARIN MURARI, FUJIO SATO

\author{
Eduardo N. Asada* \\ easada@usp.br \\ *Universidade São Paulo \\ Escola de Engenharia de São Carlos - Departamento de Engenharia Elétrica e de Computação \\ Av. Trabalhador São-carlense, 400 \\ CEP 13.566-590 - São Carlos - SP
}

BARRETO, G., CASTRO JUNIOR, C. A de., MURARI, C. A. F., SATO, F. Circuitos de Corrente Alternada: Fundamentos e Prática. 1. ${ }^{a}$ ed, São Paulo: Oficina de Textos, 2012. 262 páginas. ISBN 978-85-7975-044-1.

\section{INTRODUÇÃO}

O presente livro reúne a experiência dos autores em ministrar disciplinas de teoria e laboratório sobre conceitos básicos de eletricidade, com ênfase em circuitos de corrente alternada, para alunos dos cursos de Engenharia. A linguagem clara e objetiva e os exemplos relacionados com práticas de laboratório permitem o emprego deste livro como fonte de referência tanto para o ensino superior como no nível técnico.

Alguns aspectos que se destacam nesse livro são os vários exemplos e exercícios que remetem a situações práticas seguidas de uma explicação clara que instigam a curiosidade do leitor. São também destaque as ilustrações de boa qualidade, fotos de componentes e de montagens de experimentos e os vídeos produzidos pelos próprios autores que ilustram conceitos e demonstrações experimentais e estão disponíveis na página do livro na internet.

\section{PÚBLICO ALVO}

O livro é recomendado para todos os cursos de Engenharia. Seu conteúdo pode ser uma referência também para cursos técnicos ou para pessoas interessadas nos aspectos básicos de circuitos de corrente alternada e instalações elétricas. Os prérequisitos desejáveis para a leitura são: Física Geral, Física Experimental, Números Complexos e Circuitos Elétricos.

\section{CONTEÚDO E ESTRUTURA DO LIVRO}

O livro é estruturado em $10 \mathrm{ca}-$ pítulos. A sua organização lógica segue a estrutura de um curso de eletricidade básica para Engenharia que congrega práticas de laboratório. Por essa razão, o livro inicia com os conceitos básicos, passa-se para circuitos alternados e suas características, métodos de análise, circuitos trifásicos, transformadores e máquinas elétricas. Em

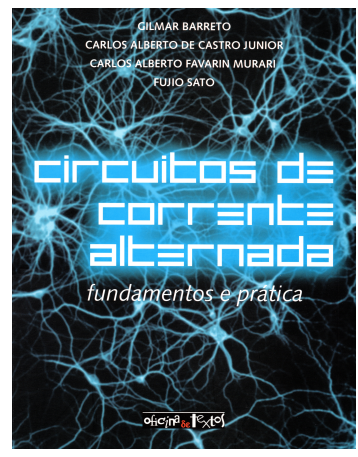
cada tópico, há exemplos que descrevem práticas experimentais, como por exemplo, a co- 
nexão das pontas de prova para visualização de formas de onda no osciloscópio (Capítulo 2), ou a forma de conexão de wattímetros para a medição indireta de potência reativa trifásica (Capítulo 7). Há um equilíbrio entre o rigor formal e a exemplificação dos conceitos por meio experimental. A Bibliografia relativa ao assunto abordado está posicionada ao final de cada capítulo. Os capítulos do livro são:

\section{Conceitos básicos}

2. Formas de ondas

3. Resistor, indutor e capacitor em circuitos elétricos

4. Conceitos de fasor e impedância

5. Potências em circuitos de corrente alternada

6. Circuitos trifásicos

7. Potências em circuitos trifásicos

8. Transformadores

9. Acionamento e proteção em instalações elétricas

10. Motores e geradores

O Capítulo 1 situa o livro na área de eletrotécnica. São descritos os sistemas de energia elétrica e circuitos de corrente alternada e são apresentadas algumas propriedades típicas. Há também um enfoque especial sobre os cuidados necessários para a realização de medições de grandezas elétricas. As leis fundamentais são apresentadas resumidamente, nomeadamente a Lei de Ohm e a 1. ${ }^{\mathrm{a}}$ e a $2{ }^{\mathrm{a}}$ Leis de Kirchhoff. Não são apresentados teoremas ou outras propriedades de circuitos elétricos.

No Capítulo 2 é definida a forma de onda alternada e como ela é representada qualitativamente. São apresentadas grandezas utilizadas para descrever a forma de onda da tensão. O conceito de valor eficaz da onda é explicado e apresentase exemplos experimentais com osciloscópio de dois canais para visualização em tela.

No Capítulo 3 são descritos os componentes: resistor, indutor e capacitor e os seus efeitos em um circuito c.a.. O comportamento em regime permanente para cada uma das combinações de montagem com esses componentes são descritos pela resolução da equação diferencial associada.

No Capítulo 4 são desenvolvidos os conceitos de fasor e impedância como parte do método de resolução de circuitos alternados. Números complexos e suas propriedades são revisados e relacionados com o conceito de fasor e impedância, que por sua vez são aplicados aos componentes resistor, indutor e capacitor. Por meio de exemplos mostra-se a validade das Leis de Kirchhoff na forma fasorial. O capítulo termina com a representação de diagramas fasoriais.

No Capítulo 5 o tema é a potência em circuitos c.a. monofásicos. São definidos a potência complexa e o fator de potência e como o tipo de carga elétrica afeta essas grandezas. A importância do ajuste de fator de potência é destacada por meio de exemplos que descrevem diferentes situações práticas e relacionam com a legislação vigente.

No Capítulo 6 o enfoque é a explicação do sistema trifásico e suas particularidades. São destacadas as diferenças com o sistema monofásico, formas de conexão estrela-triângulo, as relações de magnitude de tensão e de corrente em função da ligação e aborda-se as condições de carga equilibrada e desequilibrada.

No Capítulo 7 desenvolve-se as potências trifásicas. Além das expressões de potência, o destaque fica para os procedimentos de medição de potência com wattímetros com conexões de diferentes números de fios e conexões de cargas diferentes. São abordados os procedimentos de medição de potência reativa trifásica, feita indiretamente, por wattímetros em situação de carga equilibrada e desequilibrada. O capítulo termina com noções sobre demanda e medição de energia elétrica.

No Capítulo 8 são apresentados os fundamentos básicos de transformadores. São abordados o transformador monofásico no modo isolador e autotransformador. São discutidas também as diferenças entre o modelo ideal e o modelo real por meio de circuito equivalente. O capítulo finaliza com as possíveis conexões de um transformador trifásico e seu papel na transmissão e distribuição de energia elétrica.

No Capítulo 9 apresentam-se aspectos práticos de instalações elétricas de baixa tensão com ênfase na proteção e segurança. Após a descrição de sistemas de distribuição e normas vigentes para instalações de baixa tensão, são apresentados esquemas de aterramento, seguido de outros tópicos como dispositivos de proteção e cuidados com choque elétrico. O capítulo finaliza abordando sobre diferentes tipos de lâmpadas elétricas e formas de acionamento.

O Capítulo 10 trata de princípios de conversão eletromecânica de energia. São abordados os motores c.a. de indução e síncrono. O funcionamento, a forma de acionamento de motores c.c. e a classificação também são apresentados. Diagramas de ligação dos enrolamentos dos motores em função dos dados de placa também são analisados. Neste capítulo há utilização de várias figuras ilustrativas que facilitam a compreensão do leitor. 


\section{EXEMPLOS E EXERCÍCIOS}

Nos exemplos presentes em todos os capítulos há a preocupação de se destacar os conceitos presentes. Vários deles servem como práticas de laboratório ou representam problemas existentes no cotidiano, o que torna os conceitos menos abstratos. Há exercícios ao final de cada capítulo e neles são comuns questões de cunho mais prático como o esboço para montagem de circuitos. Para os exercícios que envolvem cálculos, são apresentadas as respostas.

\section{CONCLUSÃO}

O livro representa uma preciosa fonte de referência para uma matéria presente na maioria dos cursos de Engenharia. Há uma estreita conexão entre teoria e experimentos que auxiliam a compreensão dos conceitos. O livro é didático pois relaciona o conteúdo teórico a exemplos ricos em ilustrações e que muitas vezes estão presentes no cotidiano do leitor e são descritos em uma linguagem clara e objetiva. 